\title{
Plasma bilirubin and serum free fatty acids after myocardial infarction
}

\author{
R. E. COWAN* \\ M.D., M.R.C.P. \\ R. P. H. THOMPSON \\ D.M., F.R.C.P. \\ J. P. KAYE \\ R. J. C. Hall \\ Ph.D., B.Sc. \\ M.D., M.R.C.P.
}

The Gastrointestinal Laboratory, Rayne Institute, and the Department of Chemical Pathology, St Thomas' Hospital, London, S.E.1

\begin{abstract}
Summary
Fasting concentrations of plasma bilirubin were measured in 34 patients on admission to hospital and daily for 7 days after uncomplicated myocardial infarction. Mean concentrations increased significantly to reach maximum levels on the second day after admission, and fell during the following 5 days to reach the admission level by the 7th day. Unconjugated bilirubin accounted for most of this rise. Serum concentrations of free fatty acids (FFA), measured simultaneously in 12 patients, were highest within $12 \mathrm{hr}$ of the onset of symptoms, when their level was significantly higher than at any time after the first day. It is suggested that the transient hyperbilirubinaemia after uncomplicated myocardial infarction is frequent and may result from interference by FFA with bilirubin metabolism.
\end{abstract}

\section{Introduction}

Transient abnormalities of liver function tests have been reported after acute myocardial infarction even in the absence of severe haemodynamic changes (Aber et al., 1966; Das, Nussbaum and Leff, 1974). Observing raised bilirubin concentrations in the first few days after myocardial infarction, the authors investigated the frequency of this phenomenon by measuring total and conjugated bilirubin in consecutive cases of uncomplicated myocardial infarction during a 2-year period and studied its mechanism by measuring serum free fatty acid (FFA: nonesterified fatty acids) concentrations and by assessing liver blood flow, using indocyanine green (ICG) plasma clearance, in some patients.

\section{Patients and methods}

Thirty-four patients were studied after giving their

\footnotetext{
* Present address and reprint requests: Department of
} Gastroenterology, The London Hospital, London El 1BB. informed and written consent. Each had suffered an acute myocardial infarction, confirmed by electrocardiography, and uncomplicated by severe heart failure, shock or cardiac arrest. Most patients received at least one i.m. injection of an opiate, and many were given nitrazepam and diazepam orally. Patients requiring heparin, isoprenaline and $8-$ adrenergic blocking drugs were excluded, since these drugs influence FFA concentrations in the blood.

Concentrations of plasma bilirubin and of serum FFA were measured in blood taken from the patients on admission to hospital, and then daily while the patients were recumbent and still fasting from the previous midnight. Daily calorie intake during the study was not formally measured.

Plasma total bilirubin concentrations were measured in 24 patients by the fully automated method of Jendrassik and Grof, the upper limit of normal being $20 \mu \mathrm{mol} / 1$ and the mean coefficient of variation $2.7 \%$. Values were not obtained on each day of the study in every patient. Plasma total bilirubin levels were also measured by a modification of the method of Michäelsson (Thompson, 1969), the upper limit of normal being $14.5 \mu \mathrm{mol} / 1$ and the mean coefficient of variation $1.6 \%$. This method was used to measure plasma total bilirubin concentrations in 19 patients (9 of the same 24 and 10 others). In 16 of these 19 patients, concentrations of conjugated bilirubin were also measured and an estimate of unconjugated bilirubin was thus obtained by subtraction. The performance of both methods was checked using reconstituted freeze-dried, quality-controlled serum containing known concentrations of bilirubin (Versatol Hi and Versatol Lo, General Diagnostics, U.S.A.).

In 12 of the second group of 19 patients FFA concentrations were estimated by a semi-automated 
fluorimetric method (Carruthers and Young, 1973), using the extraction procedure of Dole (1956). The mean coefficient of variation was $4.6 \%$. Blood for this estimation was collected into glass tubes, allowed to clot, and centrifuged at $1600 \mathrm{~g}(3000 \mathrm{rev} /$ min) for $15 \mathrm{~min}$ at $4^{\circ} \mathrm{C}$. The range of values obtained from 13 fasting and resting control subjects was 117 to $835 \mu \mathrm{mol} / \mathrm{l}$ (as stearic acid), with a mean ( \pm s.e. mean) of $359 \pm 66 \mu \mathrm{mol} / \mathrm{l}$ (Kaye, Moorhead and Wills, 1973).

To study changes in liver blood flow the plasma clearance of ICG (Hynson, Westcott and Dunning Inc., Baltimore, U.S.A.), using $0.25 \mathrm{mg} / \mathrm{kg}$ body weight given i.v., was measured in 7 of the fasting and recumbent patients on the day of admission and again on the 7th day (Wiegand, Ketterer and Rapaport, 1960). Plasma clearance of ICG is closely related to liver blood flow.

The statistical significance of the data was assessed by the two-tailed Student's $t$ test.

\section{Results}

Mean plasma total bilirubin concentrations measured by the Jendrassik method rose from $11 \cdot 3 \pm$ 1.5 (mean \pm s.e. mean, range $5 \cdot 1-22 \cdot 2) \mu \mathrm{mol} / \mathrm{l}$ on admission to a maximum of $16 \cdot 1 \pm 1 \cdot 2 \mu \mathrm{mol} / 1(42 \%$ increase, range $6.8-25.6, P<0.01$ ) on the 2 nd day, following which they fell to the mean admission level on the 7 th day $(10 \cdot 1 \pm 1 \cdot 2 \mu \mathrm{mol} / 1, P<0 \cdot 05$, Fig. 1). In 18 patients $(75 \%)$ there was a rise in total bilirubin during the study and in the remainder, maximum values of total bilirubin were above normal on admission to the study.

Similarly mean plasma total bilirubin concentrations measured by the modified Michäelsson method rose from $6 \cdot 2 \pm 0 \cdot 8 \mu \mathrm{mol} / 1$ (range 3.6-8.9) on admission to $12.1 \pm 1.4 \mu \mathrm{mol} / 1(95 \%$ increase, range 4.4 $25.7, P<0.025)$ on the 2 nd day, following which they fell to reach the mean concentration on admission by the 7 th day $(6 \cdot 2 \pm 0 \cdot 8 \mu \mathrm{mol} / 1$, range $2 \cdot 4-13 \cdot 5$, Fig. 1). In 14 patients $(74 \%)$ there was a rise in total bilirubin during the study. Mean concentrations of plasma unconjugated bilirubin in 16 patients also rose from $4 \cdot 6 \pm 1.2 \mu \mathrm{mol} / 1$ ( $49 \%$ of mean total bilirubin) on the first day after admission to $8 \cdot 0 \pm 3 \cdot 0$ $\mu \mathrm{mol} / 1$, an increase of $74 \%(67 \%$ of mean total bilirubin, n.s.) by the 2 nd day, and fell during the following 5 days to $3.4 \pm 1.0 \mu \mathrm{mol} / 1$ on the 7 th day $(55 \%$ of total bilirubin, Fig. 1). Mean concentrations of conjugated bilirubin remained unchanged during the study, except for the last 2 days when they were lower than at any other time. In only 2 of the 34 patients did the total bilirubin concentrations, by either method of measurement, fall between the day of admission and the 2 nd day, while in 16 patients $(47 \%)$ total bilirubin rose above the normal range for the method of measurement on at least one occaê sion during the 7 days' study.

Serum FFA concentrations were highest on ade mission when the mean value was $590 \pm 58 \mu$ mol/t. and fell to $260 \pm 14 \mu \mathrm{mol} / 1(56 \%$ decrease, $P<0.005$ on the 7th day (Fig. 2). The mean admission con? centration of FFA was significantly higher $(P \leqslant 0.059$ than the mean concentrations for each day after the first. Mean plasma concentrations of total bilirubi in these 12 patients rose from $6 \cdot 3 \pm 1 \cdot 1 \mu \mathrm{mol} / \mathrm{l}$ of admission to $10 \cdot 6 \pm 1 \cdot 1 \mu \mathrm{mol} / 1 \quad(68 \%$ increasers $P<0.01)$ on the 2 nd day, followed by a steady fall to the admission level on the 7 th day $(6.5 \pm 1 \cdot 0 \mu \mathrm{mol} / \mathrm{F}$, Fig. 2).

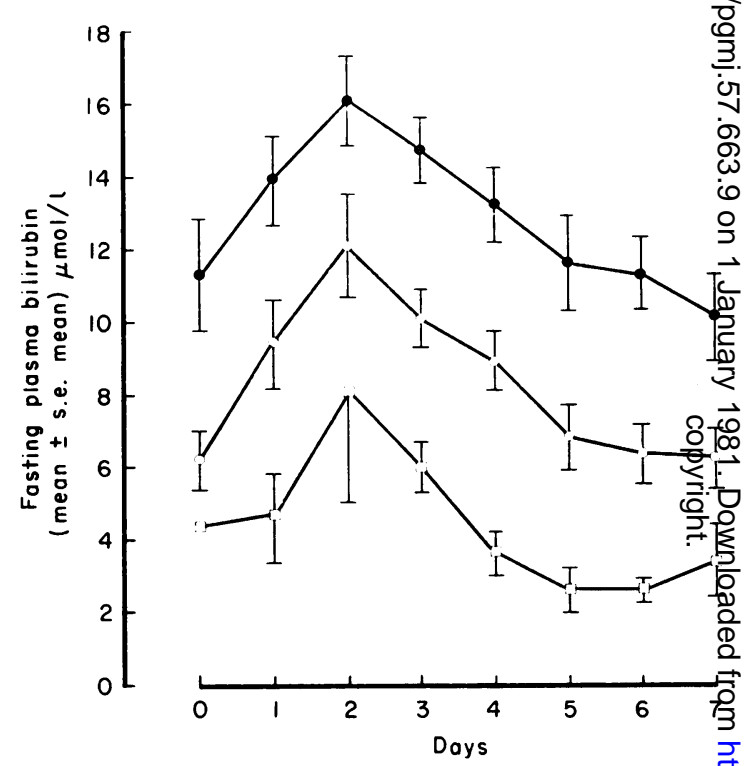

FIG. 1. Fasting plasma total bilirubin concentrations (mean \pm s.e. mean), measured by the methods of Jendrassik and Grof ( $-\mathrm{O}$ ) and Michäelsson $(\mathrm{O}-\mathrm{O}$ ), and fasting plasma unconjugated bilirubin concentrations (mean \pm s.e. mean) by the Michäelsson method ( $\square-\square$ ), on admission (day 0 ) and daily for 7 days in 34 patients after myocardial infarction. $(1 \mu \mathrm{mol} / 1$ bilirubin $=0.058 \mathrm{mg} / \mathrm{dl}$ ).

The mean plasma clearance of ICG in the $\stackrel{P}{P}$ patients was $404 \pm 53 \mathrm{ml} / \mathrm{min}$ on admission and by the 7 th day had increased to $576 \pm 75 \mathrm{ml} / \mathrm{min}$. This is an increase of $43 \%(P<0.025)$, or $49 \%$ wheno clearance is measured in relation to body weight. In 6 of the 7 patients studied, ICG clearance was highern on the 7 th day than on admission.

\section{Discussion}

This study demonstrates that following an uncomplicated myocardial infarction there is usually rise in the concentration of total bilirubin in plasma, the majority of which is unconjugated bilirubin. In 


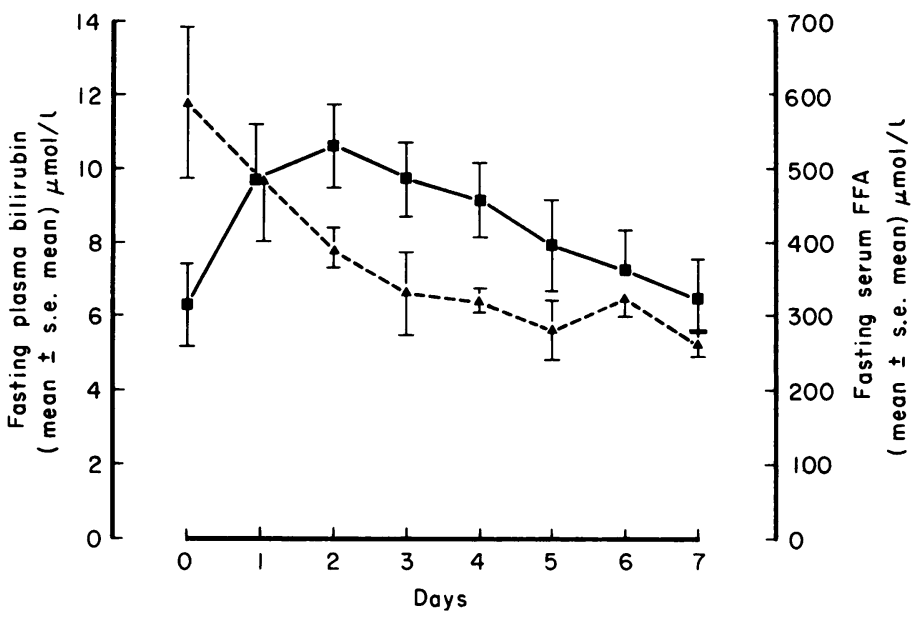

FIG. 2. Fasting plasma total bilirubin concentrations (mean \pm s.e. mean) ( $\mathbf{\square}-\mathbf{E})$, measured by the Michäelsson method, and fasting serum FFA concentrations (mean \pm s.e. mean) ( $\Delta-\Delta)$, on admission (day 0$)$ and daily for 7 days in 12 patients after myocardial infarction. $(1 \mu \mathrm{mol} / \mathrm{l}$ bilirubin $=0.058 \mathrm{mg} / \mathrm{dl} ; 1 \mu \mathrm{mol} / 1 \mathrm{FFA}=0.028 \mathrm{mg} / \mathrm{dl})$.

almost $50 \%$ of the patients studied, total bilirubin rose to above the upper limit of normal but the changes in bilirubin are usually too small to be useful in the diagnosis of an infarction. Conversely, the bilirubin concentrations are seldom high enough to suggest liver disease, although the concomitant rise in transaminase levels may confuse.

This study also confirms that FFA concentrations in the blood rise soon after myocardial infarction. Elevations in serum FFA concentrations after myocardial infarction are well recognized (Kurien and Oliver, 1966) and have been recorded within 2 to 6 hr after the onset of symptoms (Kirkeby, 1972). This suggests that peak concentrations were missed in those patients in this study who were admitted more than $6 \mathrm{hr}$ after the onset of symptoms.

A rise in unconjugated bilirubin concentration after uncomplicated myocardial infarction has not previously been described, although abnormal tests of hepatic function after myocardial infarction have been documented (Aber et al., 1966; Das et al., 1974; Rosin, 1961). Hepatic necrosis due to ischaemia has occasionally been observed (Clarke, 1950), but this is unlikely to explain the changes in bilirubin seen so frequently in this study.

There are several possible explanations for this rise in bilirubin. The lower plasma clearance of ICG on the day of admission compared with that on the 7 th day suggests that liver blood flow was reduced early in the illness, when cardiac output is usually reduced, and circulating concentrations of noradrenaline are increased. This supports the observation by Prescott, Adjepon-Yamoah and Talbot (1976) that the elimination from plasma of lignocaine, a drug that is also highly dependent on liver blood flow for its heptic uptake, is reduced even when myocardial infarction is uncomplicated by heart failure. However, the reduced liver blood flow will have only a small effect on the slow and relatively blood flowindependent hepatic clearance of unconjugated bilirubin (Berk et al., 1969). It is unlikely also that ICG itself would have affected hepatic uptake of bilirubin as its own hepatic uptake is highly dependent on liver blood flow.

Another mechanism could be increased formation of bilirubin from myoglobin released from necrotic myocardium after myocardial infarction. Kessler et al. (1975) found myoglobin in the urine on at least one occasion in $65 \%$ of patients with myocardial infarction and of these $77 \%$ had myoglobinuria on the first day of symptoms. It followed, therefore, that with the development of a rapid radioimmunoassay method for the measurement of serum myoglobin values, detection of myoglobin in serum would be proposed as a 'screening test' for the presence of myocardial infarction (Gilkeson et al., 1978). It is certainly possible that the conversion of myoglobin to bilirubin may contribute to the early rise in plasma bilirubin detected in this study, but its rapid disappearance from blood is inconsistent with the steady fall in bilirubin measured over 7 days in this study.

Reduced calorie intake results in unconjugated hyperbilirubinaemia (Bloomer et al., 1971) and might be important in the first days after myocardial infarction when patients are anorexic. However, it was probably exceptional for the daily intake of these patients to be as low as $1.67 \mathrm{~kJ}$ and bilirubin 
concentrations fell gradually and not sharply when normal food intake was restored. The concentrations of serum FFA are increased after myocardial infarction, and they might elevate bilirubin concentrations by competitive interference with hepatic bilirubin clearance, a mechanism already proposed to explain the unconjugated hyperbilirubinaemia of fasting (Cowan et al., 1977). Bilirubin and FFA concentrations did not change synchronously in this study but bilirubin concentrations will be slower than FFA to respond to changes in the rate of hepatic uptake, so plasma bilirubin will not change in parallel with the faster changes of serum FFA.

Interference by FFA with bilirubin metabolism might occur at any stage from the transport of bilirubin in the blood to its conjugation by the liver cell (Cowan et al., 1977; Odièvre, 1975) and, although there are alternative explanations for the transient unconjugated hyperbilirubinaemia after myocardial infarction, the relationship between concentrations of bilirubin and FFA found in this study supports the suggestion that bilirubin concentrations in the blood are influenced by the metabolism of FFA in the liver.

\section{Acknowledgments}

We are grateful to Dr Brian Creamer for allowing us to study those patients who were under his care. R.E.C. was in receipt of a Medical Research Council Clinical Research Fellowship.

\section{References}

Aber, C.P., Brunt, P.E., Wyn Jones, E., Richard, T.G., SHORT, A.H. \& Bernstein, V. (1966) Liver function after myocardial infarction. Lancet, $i, 1931$.

Berk, P.D., Howe, R.B., Bloomer, J.R. \& Berlin, N.I. (1969) Studies of bilirubin kinetics in normal adults. Journal of Clinical Investigation, 48, 2176.

Bloomer, J.R., BARRetr, P.V., RODKey, F.L. \& Berlin, N.I. (1971) Studies on the mechanism of fasting hyperbilirubinemia. Gastroenterology, 61, 479.

Carruthers, N. \& Young, D.A.B. (1973) Free fatty acid estimation by a semi-automated fluorimetric methodڤి Clinica chimica acta , 49, 341.

Clarke, W.T.W. (1950) Centrilobular hepatic necrosis fol lowing cardiac infarction. American Journal of Pathology 26, 249.

Cowan, R.E., Thompson, R.P.H., Kaye, J.P. \& Clark G.M. (1977) The association between fasting hyperbili rubinemia and serum non-esterified fatty acids in mano Clinical Science and Molecular Medicine, 53, 155.

Das, G., Nussbaum, H.E. \& LeFF, W.A. (1974) Hepati function in acute myocardial infarction. Journal of the American Medical Association, 230, 1558.

DoLE, V.P. (1956) The relation between non-esterified fatty acids in plasma and the metabolism of glucose. Journal of Clinical Investigation, 35, 150.

Gilkeson, G., Stone, M.J., Waterman, M., Ting, R.Gomez-Sanchez, C.E., Hull, A. \& Willerson, J.T (1978) Detection of myoglobin by radioimmunoassay in human sera: its usefulness and limitations as an emergenç room screening test for acute myocardial infarction American Heart Journal, 95, 70.

KAYE, J.P., MoORHeAD, J.F. \& Wills, M.R. (1973) Plasma lipids in patients with chronic renal failure. Clinica chimicios acta, 44, 301.

Kessler, H.A., Liebson, P.R., Mattenheimer, H. \& Adams E.C. (1975) Acute myocardial infarction diagnosed byo myoglobinuria. Archives of Internal Medicine, 135, 1181.

KIRKEBY, K. (1972) Disturbances in serum lipids and in their fatty acid composition following acute myocardial infarc के tion. Acta medica scandinavica, 192, 523.

KURIEN, V.A. \& OLIVER, M.F. (1966) Serum free fatty acids్ after acute myocardial infarction and cerebral vascular occlusion. Lancet, ii, 122.

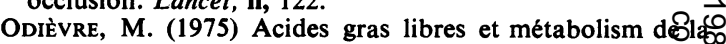
bilirubine. Biologie et gastro-entérologie, 8, 93.

Prescott, L.F., Adjepon-Yamoah, K.K. \& TAlbot, R (1976) Impaired lignocaine metabolism in patients myocardial infarction and cardiac failure. British Medica Journal, 1, 939.

Rosin, A.J. (1961) Liver function in acute myocardial infarc: tion. A study using bromsulphthalein test. British Medica $\frac{\mathrm{D}}{\mathrm{a}}$ Journal, 2, 675.

ThOMPSON, R.P.H. (1969) Modification of Michäelsson' $\vec{\delta}$ method for the measurement of plasma total bilirubins Journal of Clinical Pathology, 22, 439.

Wiegand, B.D., KeTterer, S.G. \& RAPAPORT, E. (1960) The use of indocyanine green for the evaluation of hepatic. function and blood flow in man. American Journal of Diges tive Diseases, 5, 427. 